\title{
WOMEN'S CHILDBIRTH SATISFACTION AND OBSTETRIC OUTCOMES COMPARISON BETWEEN TWO BIRTH HOSPITALS IN BARCELONA WITH DIFFERENT LEVEL OF ASSISTANCE AND COMPLEXITY
}

\author{
Pablo Rodríguez Coll ${ }^{1}(\mathbb{D})$, Rocío Casañas ${ }^{2}$, Anna Collado Palomares ${ }^{3}$ D , Gladys Maldonado \\ Aubián ${ }^{4}$, Florencio Duran Muñoz ${ }^{3}$, Xavier Espada-Trespalacios ${ }^{5}{ }^{\circledR}$, Ana Rodríguez Martínez ${ }^{6}$, \\ Ramón Escuriet Peiro 7 (D)
}

${ }^{1}$ Hospital Germans Trias i Pujol, Badalona, Barcelona, Spain

${ }^{2}$ Research Department Centre d'Higiene Mental Les Corts, Barcelona, Spain

${ }^{3}$ Vall D'Hebron Barcelona Hospital Campus, Barcelona, Spain

${ }^{4}$ Fundació Sanitària Mollet, Mollet del Vallés, Barcelona, Spain

${ }^{5}$ Fundació Hospital Asil de Granollers, Granollers, Barcelona, Spain

${ }^{6}$ Santa Lucia General University Hospital, Murcia Health Service, Cartagena, Murcia, Spain

${ }^{7}$ Health and Integrated Care division, Catalan Health Service, Barcelona, Spain

Received August 9, 2020; Accepted December 28, 2020. Copyright: This is an open access article under the CC BY-NC-4.0 license.

\begin{abstract}
Aim: Barcelona Hospital Campus Vall D’Hebron (Hospital A) and Hospital Mollet (Hospital B) provide women with humanized maternity care, but there are differences in dimension and complexity. This study describes the obstetrical results and women's childbirth satisfaction of these two Spanish hospitals. Design: A correlational descriptive study was conducted with 194 postpartum women. Methods: Satisfaction and birth experience were evaluated using the CEQ-E and the MCSRSS questionnaires. A bivariate and discriminant analysis was conducted to evaluate the relationship between satisfaction and the recorded variables. Results: There were significant differences between both hospitals in prenatal class attendance $(\mathrm{p}=0.006)$, same midwife during all process $(\mathrm{p}=0.000)$, and mode of delivery $(\mathrm{p}=0.009)$. Significant association was found among overall satisfaction and immediate breastfeeding in the delivery room $(p=0.050)$, skin-to-skin contact $(p=0.004)$, beginning of labour $(\mathrm{p}=0.031)$, and delivery mode $(\mathrm{p}=0.011)$. The total questionnaires scores mean of CEQ-E and MCSRSS were Hospital A 66.97 and 130.64; Hospital B 67.98 and 129.98, respectively. Women at both hospitals were satisfied with different aspects. Conclusion: Despite obtaining similar results in both hospitals, there are better obstetrical outcomes in hospital B with less complexity. However, women's satisfaction scores are slightly different in certain questionnaires subscales between both hospitals.
\end{abstract}

Keywords: childbirth, hospital, questionnaire, satisfaction, women.

\section{Introduction}

The birth process represents a unique and special moment in a couple's life when the new roles of father and mother are adopted (Tedesco et al., 2004). Multiple studies (Conesa Ferrer et al., 2016; Goodman et al., 2004; Hodnett, 2002; Melender, 2006) associate birth satisfaction with fulfilling personal expectations, being in control during childbirth, receiving detailed and complete information related to the birth process so pregnant women can participate in the decision-making process, being accompanied by a person of their choice, receiving support from and interacting with

Corresponding author: Pablo Rodríguez Coll, Hospital Germans Trias i Pujol, Carretera de Canyet s/n, 08916, Badalona, Barcelona, Spain; email: pablo.rodriguez.coll@gmail.com health professionals, focusing on pain management and perception during birth, and experiencing the physical comfort of the postnatal ward, as well as obstetrics factors such as antenatal class assistance, and the onset and type of labour. On the other hand, birth dissatisfaction can also provoke a preference for $\mathrm{C}$-section in future births, negative feelings toward breastfeeding, worse postpartum psychological adaptation, and also a higher abortions rate (Harvey et al., 2002).

Taking into account the consequences about birth satisfaction described above, it is necessary to investigate which factors related to women's childbirth satisfaction as a maternity care quality standard to help women achieve positive birth experiences (Mei et al., 2016). Related to quality 
indicators of maternity services, Biurrun Garrido and Goberna Tricas (2013) identified three crucial factors that women consider essential: hospital environment security, the human dimension between health professionals and pregnant women, and structural aspects.

In this context, it is necessary to count with tools to evaluate birth satisfaction. Questionnaires for assessing birth experience have been created in many languages; however, most of them have been designed and used in a context very different from the Spanish one. The most important ones are the Mackey Childbirth Satisfaction Rating Scale Spanish (MCSRSS) (Caballero et al., 2016) and the Childbirth Experience Questionnaire (CEQ-E) (Soriano-Vidal et al., 2016) in their Spanish validated versions. They are useful instruments for measuring isolated childbirth aspects or birth satisfaction only in firsttime mothers. As a multidimensional questionnaire, the Questionnaire for Assessing Childbirth Experience (QACE) (Carquillat et al., 2017) assesses four important aspects related to childbirth experience, but at present is only available in English and French.

The concept of "Humanizing Birth" appeared for the first time in a conference held in Brazil in the year 2000 (Brasil Ministry of Health, 2002). It places women in labour in the centre of the process, letting them participate in birth decisions and promoting their autonomy, beliefs, and feelings. However, hospitals cannot always assure this new childbirth care model; among the barriers against this paradigm are factors such as university hospitals, the lack of midwife authority in hospitals, limited staff resources, and a high level of unnecessary medical interventions (Behruzi et al., 2011; Senti \& LeMire, 2011).

International organizations implemented new guidelines like the World Health Organization intrapartum care initiative (World Health Organization [WHO], 2018). Spain also adhered to this tendency and developed new guidelines and initiatives, based on recent scientific evidence, such as: "Normal Birth Initiative" (FAME, 2006) or Care Strategy for Normal Childbirth (Spanish Ministry of Health and Consumer's Affaires, 2008), which changed professionals and women minds regarding birth assistance. Some years later, the WHO (2016), established a guideline composed of antenatal care recommendations to prioritize person-centred health and well-being for pregnant women and newborns, enhancing their experience of pregnancy and ensuring respectful maternity care.

\begin{abstract}
Aim
The objective of this study was to identify if there were differences in the factors related to childbirth satisfaction and / or childbirth experience between both birth hospitals with different levels of assistance and complexity and also to contrast the obstetrical results.
\end{abstract}

\section{Methods}

\section{Design}

A co-relational, cross-sectional descriptive study was conducted.

\section{Sample}

For probabilistic sample size calculation, the granmo programme (Marrugat, 2012) was used. Accepting an alpha risk of 0.05 and a beta risk of 0.2 in a twosided test, 94 subjects were necessary for the first group, and 94 in the second, to find as statistically significant a proportion difference, expected to be of 0.95 in group one and 0.81 in group two. A dropout rate of $20 \%$ has been anticipated. It should be taken into consideration that group one is Hospital Vall D'Hebron, which assists more deliveries than Hospital de Mollet.

\section{Data collection}

\section{Study setting and participants}

The scope of this study corresponded to the Barcelona Hospital Campus Vall D'Hebron and the Hospital de Mollet, which both belong to the accredited public healthcare network but differ in dimension and complexity: the first one is an 800bed high-tech academic hospital with a high capacity to admit patients of any complexity; the second is a 160-bed regional university hospital. Both have different governance: the first one is publicly financed with a budget approved by the Catalan Parliament; the second is a non-profit foundation that contracts services with the Catalan Health Service.

One is located in the city of Barcelona (hereafter referred to as Hospital A) and the other in the city of Mollet del Vallés (hereafter referred to as Hospital B).

Following the classification by the number of births of the Care Strategy for Normal Childbirth (Spanish Ministry of Health and Consumer's Affaires, 2008) Hospital A is located at Level 4 (more than 2,400 births / year) and the other one is classified at Level 2 (more than 600 and less than 1,200 births / year).

The main differences between these birth hospitals are the presence of health sciences students in Hospital A and no medical and nursing students in Hospital B. Most of the births in Hospital B are 
attended by professional midwives, while in Hospital A births are attended by midwives, students, and / or gynaecologist residents. Both hospitals provide all women with humanized maternity care. Women in labour have multifunctional delivery rooms (labour, birth, and the postpartum period happens there). Women in labour and their companions have enough privacy for themselves. They have enough space for using birth balls and adopting different postures during the birth process. For pain relief, both hospitals also use non-pharmacological methods, such as breathing techniques, massages, warm compresses, and massages in lumbosacral area music therapy, all of them provided by midwives' care. However, Hospital B also has aromatherapy and a bathtub for dilation and birth, and women in Hospital A can use a walking epidural with a small amount of anaesthesia.

Participants were recruited in the obstetric consultant, delivery room, or hospitalization ward. The information sheet and the informed consent were explained to participants.

Recruitment was continuous from April to August 2019. MCSRSS and CEQ-E were sent to the participants online between one and three months postpartum, with a questionnaire on sociodemographic and clinical variables. If the questionnaires were not answered, researchers contacted participants to remind them.

The inclusion criteria were: a) being of legal age; b) being able to understand enough Spanish language; c) having a minimum amount of computer knowledge to answer an online questionnaire. Women who could not understand the Spanish language were excluded from the study.

\section{Main Validity Measures}

Women's satisfaction was measured using MCSRSS and CEQ-E in their Spanish validated versions (Caballero et al., 2016; Soriano-Vidal et al., 2016).

MCSRSS is a questionnaire used to evaluate childbirth satisfaction. It consists of 34 items questionnaire grouped into six sub-scales: labour, birth, newborn, companion and comfort, midwife, and obstetrician. Additionally, it contains the last subscale for the global assessment of the birth experience. Items use a five-point Likert scale, ranging from "very dissatisfied" to "very satisfied". The answer format was coded as follows: 1 (very dissatisfied); 2 (dissatisfied); 3 (neither satisfied nor dissatisfied); 4 (satisfied); and 5 (very satisfied). Higher points indicate better childbirth satisfaction.

CEQ-E is used to evaluate women's perceptions about labour; moreover, this instrument can measure birth-related aspects regardless of women parity. It contains 22 statements assessing four domains of the childbirth experience, 19 items of the questionnaire using a four-point Likert Scale, and the other three a Visual Analogue Scale (VAS). To analyse the score data, the answer format of the four-point Likert scale was coded as follows: 1 (totally disagree); 2 (mostly disagree); 3 (mostly agree); and 4 (totally agree). Negatively worded item scores (items 3, 4, 9, and 11) are reversed. The VASscale scores are transformed to categorical values: $0-3=1 ; 4-6=2 ; 7-8=3$; and $9-10=4$. The scores of negative item 10 were transformed to the following categorical values: $0-2=4 ; 3-4=3$; $5-7=2$; and $8-10=1$. Higher scores indicate a better childbirth experience.

\section{Data analysis}

Student's t-test was used, with unspooled SD, to compare the means of both questionnaires. Contingency tables were tested by the $\chi^{2}$ function. A p-value of $<0.05$ was required for statistical significance. Discriminant analysis (DA) was performed to evaluate which variables contribute most to the discrimination of both hospitals. All the statistical analyses were conducted using SPSS V.25.0 for Windows.

\section{Results}

\section{Descriptive statistics}

194 women answered the questionnaires completely between one and three months after delivery. The mean age of participants was 32.78 years ( $\mathrm{SD}=5.45$; range $20-48$ ).

Study population characteristics are shown in Table 1 . The analysis showed a significant difference in the variable "education" between both hospitals $(\mathrm{p}=0.027) ; 56 \%$ of participants were women with university studies in the Hospital A, and there was only $35 \%$ in the other group. Related to attendance to prenatal classes, there was a higher percentage in Hospital A (almost 60\%) versus 20\% in Hospital B $(\mathrm{p}=0.006)$. There was also a significant difference in parity $(\mathrm{p}=0.000)$.

Table 2 lists the birth-related data. There were significant differences in the mode of delivery, the length of labour, the same midwife present throughout the process, the early skin-to-skin contact, and the food and drink allowed during labour. Although Hospital B had a higher number of normal vaginal deliveries than Hospital A (74\% vs. 54\%), the obstetrical outcomes were very similar in both hospitals. A more spontaneous beginning of labour, less instrumental births, and less length of labour 
Table 1 Socio-demographic data of the study population $(n=97)$

\begin{tabular}{|c|c|c|c|}
\hline Variable & $\begin{array}{c}\text { Barcelona Hospital } \\
\text { Campus Vall D'Hebron } \\
\text { n }(\%) \\
\end{array}$ & $\begin{array}{c}\text { Hospital de Mollet } \\
\text { n (\%) }\end{array}$ & p-value \\
\hline \multicolumn{4}{|l|}{ Age (year) } \\
\hline $19-38$ & $79(81)$ & $77(79)$ & \multirow{2}{*}{0.710} \\
\hline$\geq 38$ & $18(19)$ & $20(21)$ & \\
\hline \multicolumn{4}{|l|}{$\overline{N a t i o n a l i t y}$} \\
\hline Spain & $84(86)$ & $81(83)$ & \multirow{4}{*}{0.780} \\
\hline other European countries & $3(3)$ & $5(5)$ & \\
\hline South American & $8(9)$ & $2(2)$ & \\
\hline African & $2(2)$ & $9(10)$ & \\
\hline \multicolumn{4}{|l|}{ Marital status } \\
\hline single & $51(53)$ & $49(51)$ & \multirow{3}{*}{0.640} \\
\hline married & $42(43)$ & $46(47)$ & \\
\hline separated / divorced & $4(4)$ & $2(2)$ & \\
\hline \multicolumn{4}{|l|}{ Education } \\
\hline no studies & $2(2)$ & $1(1)$ & \multirow{4}{*}{$0.020 *$} \\
\hline elementary school & $22(22)$ & $33(34)$ & \\
\hline bachelor & $19(20)$ & $29(30)$ & \\
\hline university & $54(56)$ & $34(35)$ & \\
\hline \multicolumn{4}{|l|}{ Employment status } \\
\hline employed & $85(88)$ & $74(77)$ & \multirow{2}{*}{0.100} \\
\hline unemployed & $12(12)$ & $23(23)$ & \\
\hline \multicolumn{4}{|l|}{ Parity } \\
\hline primiparous & $65(68)$ & $38(40)$ & \multirow{2}{*}{$0.000 *$} \\
\hline multiparous & $32(33)$ & $59(60)$ & \\
\hline \multicolumn{4}{|c|}{ Prenatal classes attendance } \\
\hline yes & $58(60)$ & $39(40)$ & \multirow{2}{*}{$0.000 *$} \\
\hline no & $39(40)$ & $58(60)$ & \\
\hline \multicolumn{4}{|l|}{ Planned pregnancy } \\
\hline yes & $76(78)$ & $72(74)$ & \multirow{2}{*}{0.500} \\
\hline no & $21(21)$ & $25(25)$ & \\
\hline \multicolumn{4}{|c|}{ Voluntary interruption of pregnancy } \\
\hline 0 & $82(85)$ & $79(82)$ & \multirow{3}{*}{0.830} \\
\hline $1-2$ & $14(14)$ & $15(15)$ & \\
\hline$\geq 2$ & $1(1)$ & $3(3)$ & \\
\hline
\end{tabular}

occurred in Hospital B than in Hospital A (Table 2). It is also important to take into account thatin Hospital B, women in labour were accompanied by the same midwife in the birth process in $83 \%$ of cases versus 55\% in Hospital A.

Overall satisfaction and socio-demographic and birth data

In terms of general satisfaction, significant association was found among overall satisfaction and food and drink allowed during labour, immediate breastfeeding in the delivery room and skin-to-skin contact, the beginning of labour, and mode delivery. Results of overall satisfaction and socio-demographic and birth data are shown in Table 3.

\section{Means of both questionnaires}

The total CEQ-E questionnaire score was 92. At Hospital A, the mean score was 66.67
$(\mathrm{SD}=11.41)$ and at Hospital $\mathrm{B}$ it was 67.98 $(\mathrm{SD}=11.29)$ with no significant association $(\mathrm{p}=0.358)$.

The total MCRSS questionnaire score was 170 . At Hospital A, the mean score was 130.64 $(\mathrm{SD}=34.01)$ and at Hospital $\mathrm{B}$ it was 129.28 $(\mathrm{SD}=39.94)$ with no significant association $(\mathrm{p}=0.700)$.

\section{Comparison of the questionnaire results per item}

Tables 4 and 5 indicate the comparison of the questionnaire results per item. In the statistical analysis, statistical differences in three of the six subscales of the MCSRSS questionnaire were found: obstetrician, newborn, and companion and comfort. Although most of the women in Hospital A were slightly more satisfied in most subscales, women in Hospital B were more satisfied in the midwife subscale than women in Hospital A, specifically 
Table 2 Birth related data of the study population $(n=97)$

\begin{tabular}{|c|c|c|c|c|}
\hline Variable & & $\begin{array}{c}\text { Barcelona } \\
\text { Hospital } \\
\text { Campus Vall } \\
\text { D'Hebron } \\
\text { n }(\%) \\
\end{array}$ & $\begin{array}{c}\text { Hospital de } \\
\text { Mollet } \\
\text { n }(\%)\end{array}$ & p-value \\
\hline \multirow[t]{3}{*}{ Beginning of labour } & spontaneous & $52(54)$ & $63(65)$ & \multirow{3}{*}{0.221} \\
\hline & induction & $40(41)$ & $32(33)$ & \\
\hline & scheduled c-section & $5(5)$ & $2(2)$ & \\
\hline \multirow[t]{3}{*}{ Gestational weeks } & $\leq 37$ & $3(3)$ & $0(0)$. & \multirow{3}{*}{0.176} \\
\hline & $37-41$ & $74(77)$ & $80(83)$ & \\
\hline & $>41$ & $20(20)$ & $17(17)$ & \\
\hline \multirow[t]{7}{*}{ Pain relief } & no pain relief & $2(2)$ & $1(1)$ & \multirow{7}{*}{0.055} \\
\hline & epidural / intradural & $89(91)$ & $81(83)$ & \\
\hline & $\begin{array}{l}\text { epidural and other } \\
\text { pain relief methods }\end{array}$ & $29(29)$ & $19(19)$ & \\
\hline & $\begin{array}{l}\text { use of heat and } \\
\text { lumbar massage }\end{array}$ & $0(0)$ & $1(1)$ & \\
\hline & use of birth ball & $1(1)$ & $3(3)$ & \\
\hline & shower / bathtub & $0(0)$ & $2(2)$ & \\
\hline & alternative pain relief & $5(5)$ & $9(9)$ & \\
\hline \multirow[t]{3}{*}{ Mode of delivery } & normal vaginal & $52(54)$ & $72(75)$ & \multirow{3}{*}{$0.009 *$} \\
\hline & instrumental vaginal & $44(45)$ & $22(22)$ & \\
\hline & c-section & $1(1)$ & $3(3)$ & \\
\hline \multirow[t]{4}{*}{ Length of labour (hours) } & $0-5$ & $25(25)$ & $42(43)$ & \multirow{4}{*}{$0.002 *$} \\
\hline & $5-10$ & $24(24)$ & $32(33)$ & \\
\hline & $10-15$ & $17(17)$ & $11(34)$ & \\
\hline & $>15$ & $31(31)$ & $12(12)$ & \\
\hline \multirow[t]{3}{*}{ Condition of the perineum } & intact perineum & $45(47)$ & $45(47)$ & \multirow{3}{*}{0.981} \\
\hline & any degree & $27(28)$ & $26(27)$ & \\
\hline & episiotomy & $25(25)$ & $26(26)$ & \\
\hline \multirow[t]{2}{*}{ Breastfeeding choice } & formula feeding & $11(11)$ & $11(11)$ & \multirow{2}{*}{0.803} \\
\hline & natural breastfeeding & $86(89)$ & $86(89)$ & \\
\hline \multirow[t]{2}{*}{ Immediate breastfeeding in the delivery room } & yes & $74(76)$ & $83(85)$ & \multirow{2}{*}{0.208} \\
\hline & no & $13(13)$ & $11(11)$ & \\
\hline \multirow[t]{2}{*}{ Same midwife all birth process } & yes & $53(55)$ & $80(83)$ & \multirow{2}{*}{$0.000 *$} \\
\hline & no & $44(45)$ & $17(17)$ & \\
\hline \multirow[t]{2}{*}{ Accompanied by a person of their choice } & yes & $96(99)$ & $95(98)$ & \multirow{2}{*}{0.561} \\
\hline & no & $1(1)$ & $2(2)$ & \\
\hline \multirow[t]{2}{*}{ Immediate skin-to-skin contact } & yes & $75(78)$ & $86(89)$ & \multirow{2}{*}{$0.036^{*}$} \\
\hline & no & $22(22)$ & $11(11)$ & \\
\hline \multirow[t]{2}{*}{ Food and drink allowed during labour } & yes & $59(60)$ & $44(46)$ & \multirow{2}{*}{$0.031 *$} \\
\hline & no & $38(40)$ & $53(54)$ & \\
\hline
\end{tabular}

*Items with a statistically significant $p<0.05$

in the physical care provided by midwives (58\% vs. $47 \%$ ) and support provided by their companion during birth ( $68 \%$ vs. $58 \%)$.

On the other hand, statistical differences were found in one of the four subscales of the CEQ-E questionnaire: "own capacity".

Women in Hospital B felt more pain during childbirth than women in Hospital A. It is also important to take into account that in the subscale of professional support, women in hospital B obtained better results than in Hospital A in the time devoted to women by midwives ( $94 \%$ vs. $87 \%$ ). Furthermore, in the subscale of perceived safety, women's memories of childbirth make them feel more depressed in Hospital A than in Hospital B (48\% vs. $37 \%$ ).

The Discriminant Analysis showed which items contributed most to the discrimination of both hospitals: "personal interest and attention are given to you by obstetricians in labour and delivery", "your baby's physical condition at birth", and "your comfort level during birth". 
Table 3 General satisfaction with childbirth experience and socio-demographic and birth data Contingency table

\begin{tabular}{ll}
\hline Socio-demographic and birth data & p-value \\
\hline Ethnicity / nationality & 0.078 \\
Marital status & 0.690 \\
Education level & 0.534 \\
Employment status & 0.968 \\
Voluntary interruption of pregnancy & 0.581 \\
Prenatal classes & 0.400 \\
Age & 0.691 \\
Food and drink allowed during labour & $0.000^{*}$ \\
Planned pregnancy & 0.536 \\
Immediate breastfeeding in the delivery room & $0.050^{*}$ \\
Breastfeeding choice & 0.138 \\
Immediate skin-to-skin contact & $0.004^{*}$ \\
Same midwife all birth process & 0.069 \\
Condition of the perineum & 0.065 \\
Accompanied by a person of their choice & 0.063 \\
Pain relief & 0.643 \\
Mode of delivery & $0.011^{*}$ \\
Length of labour & 0.143 \\
Beginning of labour & $0.031^{*}$ \\
Gestational weeks & 0.870 \\
Parity & 0.615 \\
\hline
\end{tabular}

*Items with a statistically significant $p<0.05$

Table 4 Comparative of the MCSRSS questionnaire results per items and subscales

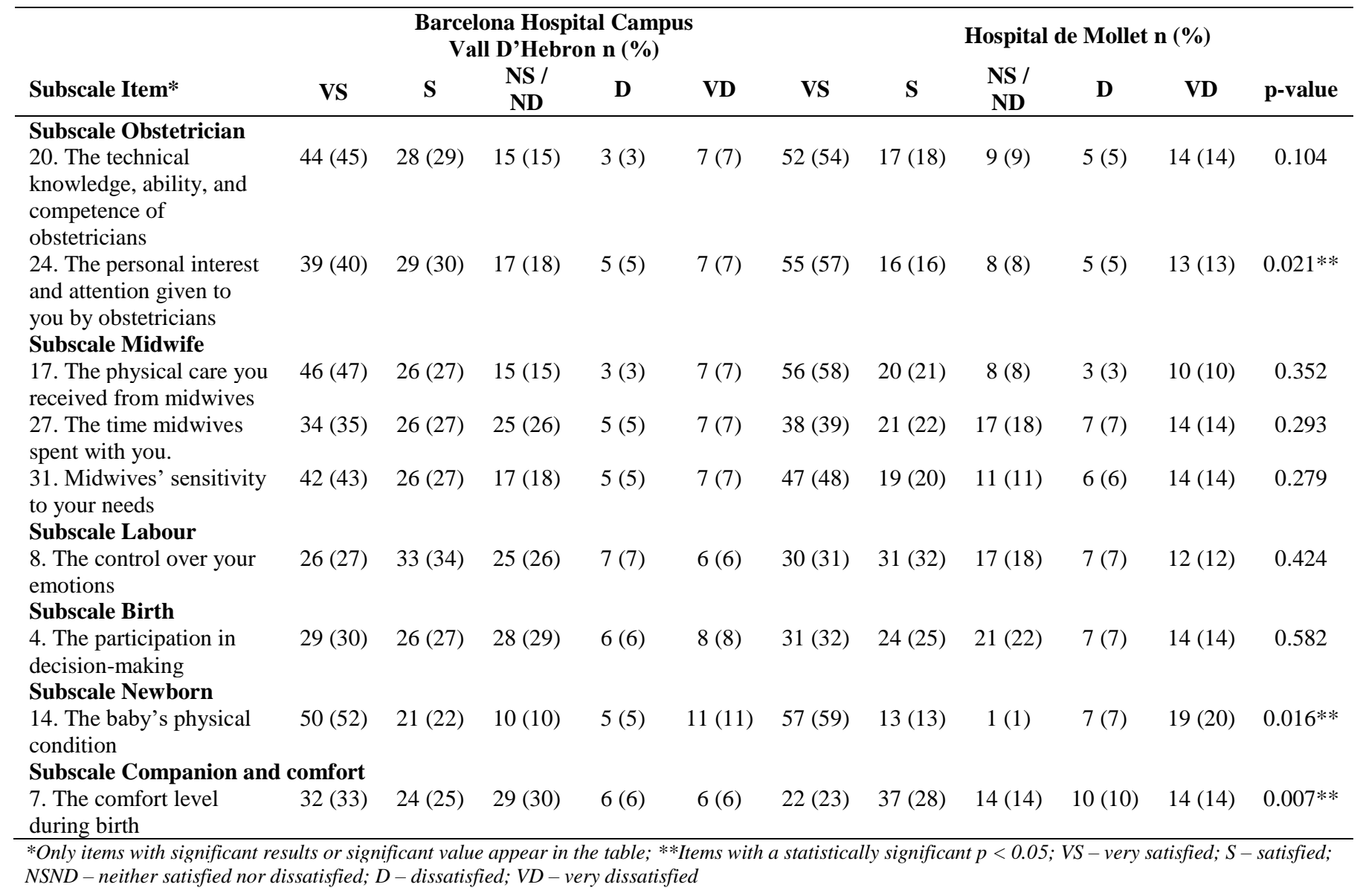


Table 5 Comparative of the CEQ-E questionnaire results per item

\begin{tabular}{|c|c|c|c|c|c|c|c|c|c|}
\hline \multirow{2}{*}{ Subscale item* } & \multicolumn{4}{|c|}{$\begin{array}{c}\text { Barcelona Hospital Campus } \\
\text { Vall D'Hebron n (\%) }\end{array}$} & \multicolumn{4}{|c|}{ Hospital de Mollet n (\%) } & \multirow[b]{2}{*}{ p-value } \\
\hline & TA & A & D & TD & TA & A & D & TD & \\
\hline $\begin{array}{l}\text { Own capacity } \\
\text { 20. As a whole, how painful } \\
\text { did you feel childbirth was? }\end{array}$ & $16(16)$ & $23(24)$ & $22(23)$ & $32(33)$ & $32(33)$ & $29(30)$ & $19(20)$ & $17(18)$ & $0.010 * *$ \\
\hline $\begin{array}{l}\text { Professional support } \\
\text { 14. My midwife devoted } \\
\text { enough time to my partner }\end{array}$ & $55(57)$ & $26(27)$ & $10(10)$ & $6(6)$ & $63(65)$ & $23(24)$ & $8(8)$ & $3(3)$ & 0.583 \\
\hline $\begin{array}{l}\text { Perceived safety } \\
8 . \text { I have many negative } \\
\text { memories from childbirth }\end{array}$ & $6(6)$ & $19(20)$ & $35(36)$ & $37(38)$ & $8(8)$ & $12(12)$ & $29(30)$ & $48(49)$ & 0.164 \\
\hline $\begin{array}{l}\text { Participation } \\
\text { 12. I felt I could have a say } \\
\text { in the choice of pain relief }\end{array}$ & $38(39)$ & $13(13)$ & $24(25)$ & $11(11)$ & $40(41)$ & $22(23)$ & $11(11)$ & $24(25)$ & 0.875 \\
\hline
\end{tabular}

*Only items with significant results or significant value appear in the table; **Items with a statistically significant $p<0.05 ;$ A - agree; D - disagree; TA - totally agree; $T D$ - totally disagree

\section{Discussion}

According to the results found in our study, there was a significant difference in the education level and attendance to prenatal classes between both hospitals; the reason could be explained by the geographical areas where both hospitals are located, in areas with lower socio-economical levels, in line with the results obtained in a recent study (Gluck et al., 2020).

Our results also showed a significant difference in the importance of being accompanied by the same midwife during the birth process. These results could have been influenced by the different hospital shifts of 12 and 24 hours. However, the existence of this continuous shifts allows for the maintenance of the quality standard of one-to-one care proposed in 2017 by the National Institute for Health and Care Excellence (NICE, 2017), since it contributes to reducing both the length of labour and the number of operative deliveries, as shown by our outcomes, which are in line with other authors' results (Bohren et al., 2017; Eke, 2017; Sehhati et al., 2012; Sydsjö et al., 2015).

Although obtaining a significant difference in attendance to prenatal classes and the fact of being accompanied by the same midwife in the birth process between both hospitals, there were no significant association among overall satisfaction and the previous variables $(\mathrm{p}=0.400$ and $\mathrm{p}=0.069$, respectively), in contrast to the results obtained by other authors (Bernitz et al., 2016; Jafari et al., 2017). Despite literature supporting the positive impact of attending prenatal classes and using the same professional during childbirth, further research is needed to identify the factors of the underuse of these aspects in our Spanish context.
In our research, results obtained when comparing overall satisfaction and the different variables revealed on the one hand - and in line with previous research (Kempe \& Vikström-Bolin, 2020) - that the mode of delivery and the beginning of labour were variables affecting childbirth satisfaction; the fact of having spontaneous labour ending in normal delivery seems to have a very positive influence on childbirth satisfaction in the mothers of our study population. On the other hand, parity was not related to childbirth satisfaction according to our results and agrees with another study carried out in a Spanish hospital (Sánchez Fortis et al., 2018).

In terms of general satisfaction, the satisfaction levels in childbirth experience of both hospitals were high: Hospital A was 73\% and Hospital B was 78\%, which are in line with the last study carried out in Cataluña, where childbirth satisfaction's levels reached $83 \%$ (Servei Català de la Salut [Catalan Health Service], 2016). In the MCSRSS questionnaire analysis results, statistical differences were found in three of the six subscales. According to our results, the highest satisfaction levels were obtained in the items "The help and support you received from a companion in birth" and "The amount of time that passed before you first held your baby", these results agree with previous studies carried out in Spain (López-Mirones et al., 2017; Marín-Morales et al., 2013).

In contrast to the original study of CEQ questionnaire development (Dencker et al., 2010), statistical differences were not found in the "perceived security" subscale. Nevertheless, the time that midwives devoted to women obtained levels of satisfaction higher than $93 \%$, especially in Hospital B. In clinical practice, satisfaction levels equal to or 
higher than $90 \%$ can be considered as a good healthcare quality indicator.

Furthermore, it is important to underscore that statistical differences were found in an item related to childbirth pain: women in Hospital B perceived to feel more pain during childbirth than women in Hospital A (66\% vs. $40 \%)$. We encourage the team leaders and policymakers of Hospital B to investigate dissatisfaction causes of pain management during birth to provide maternity quality care.

Our study has several strengths; first, it is the first study in describing and comparing childbirth satisfaction and experience in Spanish women who live in Cataluña from two different birth hospitals. Besides, methodologically, this study has used the validated Spanish versions of both questionnaires instead of modified versions of the validated one in other Spanish researches. There is, therefore, a need for broader discussion related to evaluating Spanish women's childbirth satisfaction and / or experience because very little research is carried out in our country.

The main limitation of this study was the method used for obtaining data throughout an online questionnaire after the first postpartum month. In some cases, to obtain the participants' answer and to achieve the sample size, researchers had to recall them up to three times. Furthermore, answers can also be influenced by the women's mood or the time elapsed between childbirth and the day of answering the questionnaire, as another author states (Waldenström, 2004).

Finally, it is important to mention that this paper supports the results obtained in previous researches, which showed that childbirth satisfaction is related to the mode of delivery and the beginning of labour. However, contrary to current scientific literature, there was no significant relationship between attendance to birth classes and birth satisfaction, opening the door to determine the non-attendance causes of these classes in the Spanish population.

\section{Conclusion}

In conclusion, there are better obstetrical outcomes in the hospital with less complexity than the hospital with more complexity and dimension, where most of the births are attended by health sciences students instead of skilled and experienced midwives.

In terms of birth satisfaction, similar results were obtained in both hospitals. However, women's satisfaction scores during labour, birth, and the immediate postnatal period are slightly different in certain questionnaires subscales between the participant hospitals. Healthcare professionals involved should maintain the same implication up to now to achieve the birth satisfaction levels obtained and improve them even more. Therefore, subsequent research should be focused on comparing satisfaction and childbirth experience among different birth centres where obstetric health providers and managers should promote strategies to achieve an optimum configuration of childbirth care based on the current needs of women and empowering them. It is also important to stress the importance of including women in their care and letting them participate in the decision-making process related to their birth.

\section{Ethical aspects and conflict of interest}

The Research Ethics Committees of Vall D'Hebron Barcelona Hospital Campus and Fundació Sanitaria Mollet both reviewed and approved the study, identification numbers PR (AMI) 413/2018 approved 19/11/2018 and PR 220/2018 approved 01/12/2018 respectively. According to the Spanish General Regulation of May 242016 on data protection, it will be only used for which it was collected. All participants signed informed consent. The participants of the study were informed of the voluntariness of the study and agreed to complete the online questionnaire and also to the use of their hospital records. It was granted their confidentiality.

All authors have no conflict of interest to report.

\section{Funding}

This research received no specific grant from any funding agency, commercial or not-for-profit sectors.

\section{Acknowledgments}

First of all, we would like to express our special thanks to Vall D'Hebron Barcelona Hospital Campus and Fundació Sanitaria Mollet for allowing us to conduct this research. To collaborating researchers for all the effort and support, they have provided to us and finally, we would like to thank all of our postpartum women who have voluntarily participated in the study.

\section{Author contributions}

PRC provided the conception and design of the study, CEIC application, acquisition of data, online database creation, analysis and interpretation of data, drafting the article, revised it critically for important intellectual content, and final approval of the version to be submitted; ACP, GMA, FDM and XET declare that they have participated in the study supplying the 
acquisition of data, collecting of sample needed, drafting of manuscript and analysis and interpretation; ARM, RC and REP declare that they have participated in the study being responsible for reviewing the article critically for important intellectual content; and final approval of the version to be submitted.

\section{References}

Behruzi, R., Hatem, M., Goulet, L., \& Fraser, W. (2011). The facilitating factors and barriers encountered in the adoption of a humanized birth care approach in a highly specialized university affiliated hospital. BMC Women's Health, 11, 53. https://doi.org/10.1186/1472-6874-11-53

Bernitz, S., Øian, P., Sandvik, L., \& Blix, E. (2016). Evaluation of satisfaction with care in a midwifery unit and an obstetric unit: a randomized controlled trial of low-risk women. BMC Pregnancy and Childbirth, 16, 143. https://doi.org/10.1186/s12884-016-0932-X

Biurrun Garrido, A., \& Goberna Tricas, J. (2013). La humanización del trabajo de parto: necesidad de definir el concepto. Revisión bibliográfica [Humanising the job of childbirth: the need for a definition of the concept. Review of the bibliography]. Matronas Profesión, 14(2), 62-66.

Bohren, M. A., Hofmeyr, G. J., Sakala, C., Fukuzawa, R. K., \& Cuthbert, A. (2017). Continuous support for women during childbirth. Cochrane Database of Systematic Reviews, 7, CD003766.

https://doi.org/10.1002/14651858.CD003766.pub6

Brasil Ministry of Health. (2002). Programa Humanização do parto [Birth humanization programme].

http://bvsms.saude.gov.br/bvs/publicacoes/parto.pdf

Caballero, P., Delgado-García, B. E., Orts-Cortes, I., Moncho, J., Pereyra-Zamora, P., \& Nolasco, A. (2016). Validation of the Spanish version of Mackey childbirth satisfaction rating scale. BMC Pregnancy and Childbirth, 16, 78. https://doi.org/10.1186/s12884-016-0862-7

Carquillat, P., Vendittelli, F., Perneger, T., \& Guittier, M. J. (2017). Development of a questionnaire for assessing the childbirth experience (QACE). BMC Pregnancy and Childbirth, 17, 279. https://doi.org/10.1186/s12884-0171462-x

Conesa Ferrer, M. B., Canteras Jordana, M., Ballesteros Meseguer, C., Carrillo García, C., \& Martínez Roche, M. E. (2016). Comparative study analysing women's childbirth satisfaction and obstetric outcomes across two different models of maternity care. BMJ Open, 6, e011362. https://doi.org/10.1136/bmjopen-2016-011362

Dencker, A., Taft, C., Bergqvist, L., Lilja, H., \& Berg, M. (2010). Childbirth experience questionnaire (CEQ): development and evaluation of a multidimensional instrument. BMC Pregnancy and Childbirth, 10, 81. https://doi.org/10.1186/1471-2393-10-81

Eke, A. C. (2017). How does continuous support affect outcomes for pregnant women during childbirth? Cochrane Database of Systematic Reviews, 7, CD003766. https://doi.org/10.1002/cca.1851

FAME (Federación de Asociaciones de Matronas de España) [Federation of Spanish Midwives' Associations]. (2006, June). Iniciativa al Parto Normal. Documento de Consenso [Normal Birth Initiative. Consenus Document]. https://www.federacion-matronas.org/informacion-de- interes-para-profesionales/iniciativa-parto-normal-de-lafamel

Gluck, O., Pinchas-Cohen, T., Hiaev, Z., Rubinstein, H., Bar, J., \& Kovo, M. (2020). The impact of childbirth education classes on delivery outcome. International Journal of Gynecology \& Obstetrics, 148(3), 300-304.

https://doi.org/10.1002/ijgo.13016

Goodman, P., Mackey, M. C., \& Tavakoli, A. S. (2004). Factors related to childbirth satisfaction. Journal of Advanced Nursing, 46(2), 212-219. https://doi.org/10.1111/j.1365-2648.2003.02981.x

Harvey, S., Rach, D., Stainton, M. C., Jarrell, J., \& Brant, R. (2002). Evaluation of satisfaction with midwifery care. Midwifery, 18(4), 260-267.

https://doi.org/10.1054/midw.2002.0317

Hodnett, E. D. (2002). Pain and women's satisfaction with the experience of childbirth: a systematic review. American Journal of Obstetrics and Gynecology, 186(Suppl 5), 160 172. https://doi.org/10.1016/S0002-9378(02)70189-0

Jafari, E., Mohebbi, P., \& Mazloomzadeh, S. (2017). Factors related to women's childbirth satisfaction in physiologic and routine childbirth groups. Iranian Journal of Nursing and Midwifery Research, 22(3), 219-224.

Kempe, P., \& Vikström-Bolin, M. (2020). Women's satisfaction with the birthing experience in relation to duration of labour, obstetric interventions and mode of birth. European Journal of Obstetrics and Gynecology and Reproductive Biology, 246, 156-159. https://doi.org/10.1016/j.ejogrb.2020.01.041

López-Mirones, M., Alonso-Salcines, A., Terán-Muñoz, O., García-Gonzáles, C., Laurrieta-Saiz, I., \& GonzálezMaestro, M. (2017). Satisfacción materna en el área de partos según la escala Mackey [Maternal satisfaction according to the Mackey scale]. Nuberos Cientifica, 3(21), 36-43.

Marín-Morales, D., Carmona-Monge, F. J., Peñacoba-Puente, C., Olmos Albacete, R., \& Toro Molina, S. (2013). Factor structure, validity, and reliability of the Spanish version of the women's views of birth labour satisfaction questionnaire. Midwifery, 29(12), 1339-1345. https://doi.org/10.1016/j.midw.2012.12.015

Marrugat, J. (2012, April). Calculadora de Tamaño muestral GRANMO [GRANMO sample size calculator]. Barcelona Medical Research Municipal Institute.

https://www.imim.es/ofertadeserveis/softwarepublic/granmo/

Mei, J. Y., Afshar, Y., Gregory, K. D., Kilpatrick, S. J., \& Esakoff, T. F. (2016). Birth plans: what matters for birth experience satisfaction. Birth, 43(2), 144-150.

https://doi.org/10.1111/birt.12226

Melender, H.-L. (2006). What constitutes a good childbirth? A qualitative study of pregnant Finnish women. Journal of Midwifery and Women's Health, 51(5), 331-339. https://doi.org/10.1016/j.jmwh.2006.02.009

NICE (National Institute for Healthcare and Excelence). (2017, February). Quality statement 2: One-to-one care | Intrapartum care | Quality standards. U. K. National Institute for Healthcare and Excelence. https://www.nice.org.uk/guidance/qs105/chapter/Qualitystatement-2-One-to-one-care

Sánchez Fortis, A., Sánchez Fortis, C., \& Pozo Cano, M. D. (2018). Satisfacción de las mujeres con la atención al parto [Satisfaction of women with delivery care]. Matronas Hoy, 1(6), 31-36. 
Sehhati, F., Najjarzadeh, M., Seyyedrasouli, A., \& Zamanzadeh, V. (2012). Effect of continuous midwifery care on length of labor. Journal of Caring Sciences, 1(1), 47-52. https://doi.org/10.5681/jcs.2012.007

Senti, J., \& LeMire, S. D. (2011). Patient satisfaction with birthing center nursing care and factors associated with likelihood to recommend institution. Journal of Nursing Care Quality, 26(2), 178-185. https://doi.org/10.1097/NCQ.0b013e3181fe93e6

Servei Català de la Salut [Catalan Health Service]. (2016, October). Estudi satisfacció embaràs part puerperi 2016 [2016 Birth and puerperium satisfaction study]. Catalan Health Service CatSalut.

https://catsalut.gencat.cat/web/.content/minisite/catsalut/ciut adania/serveis_atencio_salut/valoracio_serveis_atencio_salu t/enquestes_satisfaccio/atencio_embaras_part_puerperi/201 6/EPP_2016.pdf

Soriano-Vidal, F. J., Oliver-Roig, A., Cabrero-García, J., Congost-Maestre, N., Dencker, A., \& Richart-Martínez, M. (2016). The Spanish version of the Childbirth Experience Questionnaire (CEQ-E): reliability and validity assessment. BMC Pregnancy and Childbirth, 16, 372. https://doi.org/10.1186/s12884-016-1100-Z

Spanish Ministry of Health and Consumer's Affaires. (2008). Strategy for Assistance at Normal Childbirth in the National Health System 2007.

https://www.mscbs.gob.es/organizacion/sns/planCalidadSN
S/pdf/equidad/estrategiaPartoNormalEnglish.pdf

Sydsjö, G., Blomberg, M., Palmquist, S., Angerbjörn, L., Bladh, M., \& Josefsson, A. (2015). Effects of continuous midwifery labour support for women with severe fear of childbirth. BMC Pregnancy and Childbirth, 15, 115. https://doi.org/10.1186/s12884-015-0548-6

Tedesco, R. P., Maia Filho, N. L., Mathias, L., Benez, A. L., de Castro, V. C. L., Bourroul, G. M., \& dos Reis, F. I. (2004). Fatores determinantes para as expectativas de primigestas acerca da via de parto [Primigravid expectations about the delivery method and the causal factors for their choice]. Revista Brasileira de Ginecologia e Obstetrícia, 26(10), 791-798. $\quad$ https://doi.org/10.1590/s010072032004001000006

Waldenström, U. (2004). Why do some women change their opinion about childbirth over time? Birth, 31(2), 102-107. https://doi.org/10.1111/j.0730-7659.2004.00287.x

WHO (World Health Organization). (2016, January). Recommendations on antenatal care for a positive pregnancy experience. World Health Organization. https://www.who.int/publications/i/item/9789241549912

WHO (World Health Organization). (2018). WHO recommendations: intrapartum care for a positive childbirth experience. World Health Organization. https://www.who.int/reproductivehealth/publications/intrapa rtum-care-guidelines/en/ 